any kind of trained assistants for any money, but even today I will undertake to state that a hospital without social service is wasting money. I think it will be worth while to take a few minutes to speak of the economic side of the question, namely, the effect on economy of hospital management of having a good social service department. Dr. Smith has spoken of some of the direct medical effects, such as securing proper after-care for patients who need convalescent care, seeing that they are properly placed so that their bed can be freed for another case. That is a job which often requires the assistance of the social worker. If a hospital bed on the average can be emptied for a certain type of ease three days sooner than would otherwise be the case, that would make quite a difference financially in the course of a whole year. It might increase the capacity of the hospital by ten to twenty per cent. without any additional beds.

Every physician is familiar with the case that stays on and cannot be gotten rid of. The ward sometimes has to be cleared by main force, but there are dangers to that and the patient sometimes returns. There was one case in a well-known hospital where a woman patient came back a number of times, in fact five times. Between the fourth and the fifth admissions a social service department had been established, and the department at once made an investigation of this case. It seems that there were five children in the family, living on the fourth floor of a tenement, and the mother was doing most of the work. Her diagnosis had been cardiac disease, and the explanation of the woman's recurrent returns to the hospital was pretty obvious. The superintendent studied the matter and figured that these re-admissions over a period of three years had cost the hospital $\$ 600$, which would have been enough to pay the salary of a social worker for over six months and would have saved the patient quite a good deal, incidentally. That hospital considers that report as rather good evidence that social service pays.

In cases requiring after-care,-the case of chronic ailment,- - the patients who need convincing to make them take proper treatment or undergo an operation, the case of the halfsick person requiring periods of care in the hospital or out-patient department, it seems to me that it is well to bear in mind that the func- tion of the social worker is largely a function of finding out the facts. Patients like you and me are usually ready to do something for their own benefit. But sometimes there is a hidden obstacle. Take the case of a woman who was told after a period of observation in the hospital that she needed an operation. She refused to have it, and for a time it was impossible to find out why she would not have it. An investigation by the social worker brought out the fact that her family of children was dependent on her and that the father was a drunkard. Should he go on a spree during her per. iod in the hospital her family would be broken up. She would not take that chance. The solution of the problem lay in careful work with the family to find some means of covering the situation with the aid of a friend or relative or some helper who would give the mother assurance that while she was in the hospital her family would be looked after. I mention this actual case merely as an illustration to show what can be done by social service in getting results.

The practical question of cost is usually dealt with in a hospital about to establish a social service department by appealing to the humanitarian element. A group of people interested in the hospital are asked to help and the appeal is made to them on the basis of helping the poor, of giving the patients a social worker who will render them kindly services. This is well, but I do think that we perhaps underestimate the effectiveness of the strictly business appeal on the basis of a direct contribution to medical efficiency because of the proven value of social service in actually making a given hospital equipment go further, and do more as well as better medical work.

\section{(Briginal Artirler.}

\section{HEARING TEST TO DETECT MALINGERING.}

By John F. Callahan, M.D., Brockton, Mass.

A NUMBER of young men have consulted me since the beginning of the draft for certification of lack of hearing in one ear, the certificate to be used in support of the elaim for exemption on the ground of deafness. In many of these cases there was no real loss of hearing, 


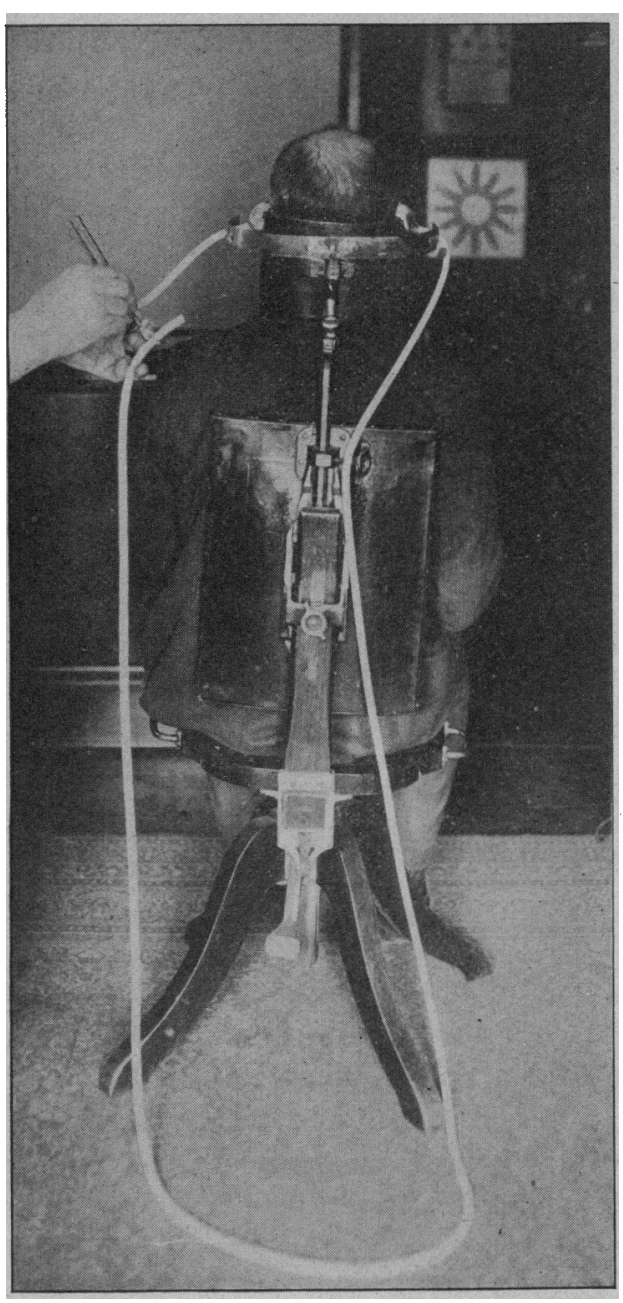

ing goes to the left ear, and as the tuning fork passes from the right half of the tubing through the neutral space to the left half of the tubing, the sound is heard in the left ear alone. The detection of feigning now becomes practicable if it takes the form of misstatements concerning the hearing in one ear.

Illustrative case No. 1. This patient heard whispering voice in good ear at eighteen feet, and in the bad ear at three feet. The tube was connected with the funnel for the good ear; and the tuning fork was heard at $7 \frac{1}{2}$ feet. The tube was then connected with the funnels for both ears. Moving the tuning fork along the tube away from the good ear it was heard only in the latter until we reached a point 30 inches from the bad ear and 54 inches from the good ear, where the patient could not tell in which ear he heard the sound. At 26 inches from the bad ear he heard it only in the bad ear, and on moving the fork back again toward the good ear he again was not able to say which ear he heard the sound when the fork was 30 inches from the bad ear and 54 inches from good ear, but two inches farther along the tube -32 inches and 52 inches-he heard it only in the good ear.

In this case the patient really had a marked difference in the hearing of his two ears, as the tests showed plainly. In normal ears the neutral space would be in the middle of the tube, and either side of this space the patient would uniformly tell us that he heard in the ear nearer the tuning fork.

Illustrative test No. 2. Patient said his hearing in left ear was perfect, but that his right ear was totally deaf. With the long "one ear" tube connected for his left ear it was found on several tests that he heard the fork up to seven and one half feet from the ear. With the same tubing connected with the funnel for the right ear he persistently held that he did not hear it even at four inches from the ear. The tube was then connected with both funnels and the tuning fork started at the left-good-ear. $\mathrm{He}$ admitted hearing the sound in the left ear until we reached a point 40 inches from the left ear, when he said thiat he could not hear it. From this point onward up to 4 inches from his right-bad-ear he claimed not to hear the sound. We then placed the tuning fork over the coupling in the tube-this point being 11 inches from his right ear and 70 inches from his left. He said he did not hear it. The coupling was taken apart and the fork again touched to the tube at the same place where he had just said he heard nothing, viz.., 71) inches from the left ear on the end that went to the left ear, and he said he heard it in his left ear. He was caught, for if his right ear had been deaf, he would have heard the sound in his left ear at this point and at every other point up to 84 inches from his left ear while the tubing was still connected with both fuinnels. He reported not hearing the sound to the right of the neutral space because he was determined to give a negative answer whenever he heard the sound in his right ear.

If the eight foot tubing be cut about 14 inches from one end and joined by a simple wooden coupling-a meat skewer cut* to two inches in length and tapered at each end--it will make simpler the determination as to which ear the sound is heard in. For example, if the subject admits hearing the sound about a foot

* Couplings made of hard rubber tubing are more suitable than meat skewers. 
from his bad ear, we can uncouple the tube at the coupling and by touching the fork to one end or the other, find out which ear is hearing it at that point, and by repeating this test see if his answers are uniform. All the tests are done behind the patient who does not know whether two tubes or one are being used, nor does he know which ear is nearer the tuning fork. And all the tests depend on the -fact that the patient hears only in the ear in kichich the sound is louder. We may cut the tube at one or several places connecting it with the wooden coupling as they are about equat to the tubing that $I$ use in the conduction of the vibration.

The following modification ef the above method has been used recently to détermins the degree of hearing in the bad ear. Take two tubes each the length of the hearing in the good ear. Attach to the funnels of zitiner ear Touch the end of the tube to the good eat with a tuning fork, and at the same time toweh the tubing to the bad ear with a similar tuning fork near the head. Now run down the tubing of the bad ear, being careful that the two tuning forks touch the two tubes at precisely the same time. When the sound in the bad ear-as we get away from it-becomes less than that in the good ear, the patient will not hear it at all and will hear the sound in the good ear, and he will, if malingering, then for the first time admit hearing at all. And this point will be the measure of the distance he hears with the bad ear, as we have just passed through the neutral zone at which point he was hearing the same in both ears.

The apparatus. Stiff rubber tubing, 3-16 inch inside and 6-16 inch outside diameter. Tuning forks. Funnels for each ear. Adjustable headrest with a piece of strap iron extending around to the front on either side, and having several holes through which the rubber tubing may pass to the funnels, and allow them to be opposite the ears and about one inch from the head. I always use a tube the length of which is about 6 inches shorter than the distance that he can hear the tuning fork in good ear.

If bone conduction was to be tested all we have to do is to place the funnel in contact with the cranial bones over the ear.

\section{Rank ZRuirum.}

Clinical Diagnosis. By James Campbel, Tom, Ph.B., M.D. Fourth Edition. Philadelphia and London: W. B. Saunders Company. 1918.

The fourth edition of "Clinical Diagnosis" has been enlarged and the illustrations have been revised and increased. As in previous editions, emphasis has been laid chiefly upon methods and microscopic morphology. The main sources of error in microseopic diagnosis, such as imperfect preparation of material, iaulty manipulation of the microscopen and failure to recognize extraneous structures, artefacts, and other misleading appearances, have been given especial attention. Additions have been made in the material dealing with the ise of colorimeters and the pocket spectroscope and methods of matching blood for transfusion. New sections have been added, dealing with the new Bass and Johns concentration method for malarial parasites; the fractional method of gastric anlysis, vital staining of blood-corpuscles; resistance of red corpuscles; the mastic reaction in the spinal fluid; the Webber and Aldis method for urobilin as an aid in diagnosis of pernicious anemia; and estimation of amylase in urine and feces in diagnosis of pancreatic disease. The chapter upon sero-diagnostic methods has been revised. The illustrations, including photomicrographs and colored plates, have been carefully supervised by the author and convey a vast amount of important information.

A Manual of Personal Hygiene. Edited by Warter Pyle, A.M., M.D. Seventh Edition. Philadelphia and London: W. B. Saunders Co. 1917.

The growing demand for "A Manual of Personal Hygiene" has been met by the publication of this seventh edition, revised and enlarged. This book is an exposition of proper living upon a physiologic basis. To develop and maintain physical and mental vigor, knowledge of the normal functions of the body and methods of keeping them in healthy action is necessary. Popular instruction in the prevention of diseases, the rules of domestic and personal hygiene, should be more widely disseminated among communities. Among the subjects considered in this volume are the hy- 
and at times this was very difficult to demonstrate by the routine methods because the registrant would feign deafness so intellingently that the older methods could not be applied satisfactorily. In order to make a just deci sion in cases where $I$ was not certain of the patient's honest coöperation I evolved the following technic which has proved of great value, and appears to be absolute in its findings.

The test demonstrates not only the presence of hearing in an ear, but also the degree of hearing, and it is a test of hearing by air conduction alone. The usual methods are first employed with ticking watch, voice, and tuning fork, and records made of the results by air and by bone conduction. After this has been done I use my tube test.

It is easily demonstrated that tuning forks vibrating with the same pitch and loudness one inch from each ear are heard in each ear, but that if the fork at left ear is removed to a point three inches from the ear, this sound is lost and only the fork remaining at one inch from the right ear is heard. If now the one at the right ear is removed six inches from the ear, it will no longer be heard; but the left one, formerly not heard, will again become audible. I found that similar results are obtained if the tuning fork was placed against a rubber tubing, the latter transmitting the fork vibrations to the ear. In my first experiments I used the stethoscope, touching the bowl of the instrument with the vibrating fork and cutting off the sounds from one ear or the other by pinching one or the other arm of the tubing with a haemostat. I found that this was not satisfactory because the haemostat did not cut out all sound from the pinched side of the tubing. Also, the diaphragm of the stethoscope is unnecessary. For several months I have used simply about a seven foot length of rubber tubing, hole $3 / 16$, wall of tubing $3 / 32$ inch, to either end of which is attached an aluminum funnel. The use of lugs allows of bone conduction entering the test, as in this technic the vibrations transmitted along the tubing can be felt even by the hand and are easily transmitted through lugs to the bony parts in the region of the ear. The funnels are held to the ears, and about one inch away from them by a simple attachment on the headrest of the examining chair which allows of adjusting them to cover the ears without touching the patient.
This is important as we are concerned only with air conduction, and to prevent bone conduction from entering into the test we must be sure that no part of the apparatus comes into contact with the patient's person at any point.

I find that tuning fork $256 \mathrm{C} 1$ is heard by the normal ear when placed against the $3 / 16$ $3 / 32$ inch tubing at any point up to $7 \frac{1}{2}$ feet from the ear. With a larger size tubing the same tuning fork is heard as far away as thirty feet from a normal ear. As a routine in this test $I$ use the fork and tube of the first named sizes.

The application and results in an individual with two normal ears are as follows: The seven foot tube is connected with one funnel, the latter being placed about one inch from the right ear. The tuning fork vibrating is applied to the tubing about six inches from the ear and moved along the tube away from the ear until it is no longer heard. This will usually be about seven to seven and one half feet. The tube is now disconnected from the right funnel and attached to the left, and the same procedure followed. If normal, the left ear will also hear the sound of the fork transmitted along the tube up to seven feet or more from the ear. Now the tube is attached to both funnels. The vibrating fork is applied to the tube one foot from the right ear and moved along the tube away from the right ear and toward the left ear. It will be heard only in the right ear until it reaches a point about three to three and one half feet from the right ear, at which point it will be heard also in the left ear and will continue to be heard in both ears for a distance of about four inches in the middle of our seven feot tube. It is this space of about four to six inches in the middle of the tube that I call "the neutral space." The sound in this neutral space almost imperceptibly disappears from one ear to appear in the other, and in this space there is some doubt in the patient's mind in which ear he hears the fork. As we pass through the neutral space, the sound becomes perceptible in the left ear and is not heard in the right. It is to be noted well that whereas the right ear heard the tuning fork up to seven feet in the first part of the test, it now loses the sound of it along the same tubing at about three and one half feet because in this second instance the other end of the tub- 